\title{
Respiratory health as a predictor of questionnaire return in a sample of United States underground coalminers
}

\author{
R B TRENT, ${ }^{1 *}$ R G AMES ${ }^{2}$
}

From the Department of Sociology and Anthropology, ${ }^{1}$ West Virginia University, Morgantown, West Virginia 26506, and Health Hazards Evaluation Branch, ${ }^{2}$ California Department of Health Services, Berkeley, California 94704, USA

ABSTRACT A logistic model was used to analyse questionnaire return in a postal survey of 311 coalminers who had left their place of employment between 1977 and 1982. Three measures of respiratory health, obstruction, restriction, and presence of chronic bronchitis symptoms, were included in the model as predictors together with the possibly confounding factors of age, education, and marital and smoking status. Age was positively associated with questionnaire return $(\mathrm{p}<0.001)$. Speed of return, and whether the return was in response to a prompt, were not predicted by either the respiratory health measures or any of the other possibly confounding variables.

Response to postal questionnaires has been well reported. Research on return rates is important because the postal survey, an inexpensive technique for gathering data, is being used more and more by the medical profession as a substitute for personal interviews. Knowledge of response bias is important in determining the usefulness of the information obtained, since postal survey return rates are typically low (Babbie considers $50 \%$ adequate $^{1}$ ) and may introduce sampling bias. The magnitude and direction of response biases are generally impossible to estimate from cross sectional surveys because population parameters are seldom known.

The use of postal questionnaires in the United States goes back almost 200 years to George Washington, who conducted an agricultural crop survey in $1791 .^{2}$ The usefulness of data derived from postal questionnaires has been debated in the United States for at least 60 years. $^{3}$ Researchers have studied the sources, severity, and solutions for response bias with contradictory conclusions. So far no models exist to predict the nature, direction, and magnitude of response bias. ${ }^{4}$ Notwithstanding the lack of a generalisable model, certain issues have recurred in studies

\footnotetext{
*Present address: Division of Safety Research, National Institute for Occupational Safety and Health, 944 Chestnut Ridge Road, Morgantown, WV 26505, USA
}

Accepted 30 October 1986 of questionnaire response conducted over a diverse range of topics.

Importance of the topic to the respondent was seen to predict higher rates of return in a review analysis based on 98 separate postal questionnaire studies. ${ }^{4}$ Many studies have documented an inverse association between age and return, ${ }^{5-9}$ although in other studies return has been low among younger people, ${ }^{10}$ possibly because they are more migratory, ${ }^{11}$ or because the topic under study was less salient for them. ${ }^{12}$ Some studies have found no significant association between age and return. ${ }^{1314}$ Education has frequently been shown to have a negative correlation with return rate. ${ }^{57812}$ It is not clear to what extent the prediction of non-response by education is due to variations in salience, literacy, mobility, or other traits associated with educational status. Apart from the negative education bias, few consistent response differentials are noted on reports on postal questionnaires. Goudy, in his summary of postal questionnaire surveys, found that respondents differed significantly from non-respondents in 85 studies but that in 19 other studies there were no significant differences. ${ }^{15}$

In health research non-response to questionnaires and other non-participation is especially important because it may produce biased estimates of disease prevalence and risk exposures. ${ }^{16-18}$ Health research reports noting differentials in response to postal ques- 
tionnaires are few. One study found only small differences between respondents and non-respondents in the accuracy of reports of physician visits. ${ }^{19}$ The larger reports on health research participation (including mail surveys, interview surveys, and health screening) do not lead to any generalised conclusions about the determinants or effects of non-response.

The relation between participation and objective measures of health status is not consistent from study to study. Vernon et al in summarising recent health reports on non-participation in postal questionnaire and longitudinal design interview studies noted that non-participation is sometimes related to disease risk factors, morbidity symptoms, and subsequent mortality. ${ }^{20}$ Non-participants in some studies had higher subsequent mortality rates, ${ }^{21-23}$ but Paul et al did not find a significant subsequent mortality difference between respondents and non-respondents. ${ }^{24}$ Clark et $a l^{25}$ and Greenlick et $a l^{26}$ found negative associations between objective measures of health and participation, Criqui et al ${ }^{14}$ found a positive association, and Abramson et $a l^{27}$ and Wiley and Camacho ${ }^{28}$ found no significant associations. By contrast, self reported symptoms, as well as reports of concern over one's health, consistently predict participation in several studies. ${ }^{1427-31}$ In some studies nonparticipants were more likely to be cigarette smokers ${ }^{1432} 33$ but this finding evidently does not hold universally. ${ }^{34}$

Research on speed of return and effectiveness of using prompts for increasing return is inconclusive. Kivlin found speed of return correlated with respondent demographics, ${ }^{7}$ whereas Baur did not. ${ }^{5}$ Cigarette smokers were found to be slower to return questionnaires by Heath, ${ }^{35}$ Oakes et al, ${ }^{13}$ and Seltzer et $a l^{36}$ Oakes et al ${ }^{13}$ and Seltzer et al, ${ }^{36}$ however, found that smoking bias was diminished by the use of prompts as these increased the number of questionnaires returned. Siemiatycki and Campbell found no smoking or reported health status differences between prompted and unprompted postal questionnaire returns. ${ }^{37}$

In summary, evidence on non-participation in health surveys in general or postal questionnaire return in particular shows no consistent patterns in response by age, mortality, or smoking status. Participation appears to be higher for better educated respondents and for issues more salient to the respondent. In particular, people with disease symptoms or who report health concerns have higher postal questionnaire return rates for health questionnaires. Speed of questionnaire return and whether return is in response to a prompt may be related to cigarette smoking status, a risk exposure for some diseases. The fact that self reported symptoms or other health concerns predict participation is consistent with the more general hypothesis that participation is at least partly a function of personal salience. ${ }^{1438} 3$ 登

\section{This study}

As the review of publications shows salience to the individual to be a recurrent factor in returning ques tionnaires, it is hypothesised that miners with impaired respiratory function or with respirator $\varnothing$ symptoms will respond to a survey more readily thaط miners without impairment or symptoms, thus introducing a bias toward over estimation of ill health.

To test this hypothesis in this paper we examine thछ response to a postal questionnaire among undere ground coalminers where the baseline respiratoris parameters are known on all participants, respond? ents, and non-respondents alike. Respiratory func $\nRightarrow$ tion and symptoms constitute important areas op concern in occupational health generally and are्ड often examined in epidemiological research on under: ground coalminers.

\section{Data and methods}

As part of its research programme on undergroundo coalminers' health, the United States National Instiv tute for Occupational Safety and Health (NIOSH systematically gathers questionnaire information or personal and occupational history and respiratory symptoms, measures respiratory function through spirometry, and obtains chest radiographs. The dato used in the present-study are from a baseline group of 1116 United States white underground coalminer@ from mines in Kentucky, Colorado, and Utah. health and occupational mobility questionnaire wa posted in 1982 to miners for whom respiratory health. measures had been obtained in 1977 and who had lefg their place of employment between 1977 and $1982 \frac{}{3}$ The covering letter with the questionnaire stated that West Virginia University in cooperation with NIOSI. was doing a study of job changing among coal miners and that their participation would be greatly appre ciated. A stamped and addressed envelope was included for their reply. The dependent variable questionnaire response, is measured in three ways: (IS. whether or not the questionnaire was ever returned and for returned questionnaires (2) the speed oP return, dichotomised at the median ( 23 days fronn posting); and (3) whether a prompt (by post) was్ required to elicit return ( $31 \%$ of returned question naires were prompted).

The questionnaire included items on respondents? health, activities since leaving the mine where they? were employed in 1977, and background information The covering letter referred to an extensive NIOSH health assessment that the respondents underwent iri 1977 which entailed a detailed health and work his tory interview, spirometry, and chest radiographs. As 
an occupational group whose health is under regular $\mathrm{NIOSH}$ surveillance and whose disability benefits are often tied to a documented health condition (coalworkers' pneumoconiosis), the questionnaire was probably salient to the subject. We did not ascertain benefits status because this information was considered too sensitive. Of the baseline group of 1116 miners, 408 had left their employment since 1977. Employers provided valid addresses for 311 living miners. Sixty per cent (188 of 311 ) returned completed questionnaires. This is a high return rate for a postal questionnaire in a population with low average education ${ }^{38}$ and may indicate that the questionnaire was salient for the respondents.

The predictors of questionnaire return used in this study are spirometric measures of respiratory function and questionnaire measures of respiratory symptoms. Pulmonary function measures include forced vital capacity (FVC) and forced expiratory volume in one second $\left(\mathrm{FEV}_{1}\right)$. An obstruction index $\left(\mathrm{FEV}_{1} / \mathrm{FVC} \%\right)$ and a restriction index (FVC $v$ standard \%) were created. ${ }^{40}$ The restriction index standards are based on norms presented by Knudson et al. ${ }^{41}$ Presence of respiratory symptoms, measured by a modified British Medical Research Council (BMRC) questionnaire, ${ }^{42}$ include chronic cough ( $\geqslant 3$ months/year) and chronic phlegm ( $\geqslant 3$ months/ year). A bronchitis index was created which sums the presence of these two symptoms ${ }^{40}$ Age, education, and smoking and marital status were introduced into the regression model primarily as control variables. Education was measured by the highest number of years of school completed. Cigarette smoking status was dichotomised as "non- and ex-smoker" versus "current smoker." Marital status was dichotomised as "not currently married" versus "currently married." Descriptive values for the sample are presented in table 1. A detailed description of the NIOSH phase of the data collection has been presented elsewhere. ${ }^{43}$

To determine the effects of respiratory dysfunction and symptoms on questionnaire return, all the inde-
Table 1 Description of variables included in the logistic model

\begin{tabular}{lll}
\hline Variable & Measurement & $\begin{array}{l}\text { Descriptive } \\
\text { value }\end{array}$ \\
\hline Age & Years & Mean $=39$ \\
Education & Years & Mean $=12$ \\
Marital status & Proportion now married & $83 \%$ \\
Smoking status & Proportion now smoking & $40 \%$ \\
Obstruction & FEV $/$ FVC \% & Mean $=77$ \\
Restriction & FVC $v$ standard \% & Mean $=95$ \\
Bronchitic symptoms & $1-2$ symptoms & Mean $=0.6$ \\
\hline
\end{tabular}

pendent variables shown in table 1 were entered into a logistic regression model. Logistic regression calculates the linear association between a set of independent variables, which may be categorical or continuous, and a dichotomous dependent variable. ${ }^{44}$ The model produces regression coefficients that show the effect of each independent variable on the dichotomous dependent variable, adjusted for the simultaneous effects of the other independent variables. The significance of each independent variable's unique contribution to prediction of the dependent variable may be assessed according to the $\mathrm{Z}$ distribution. Here statistical significance of regression coefficients was tested with a two tailed test, alpha $=0.05$.

\section{Results}

Based on a model adjusted by the other predictor and control variables, older miners were more likely to return the questionnaire $(\mathrm{p}<0.001)$ (table 2 , column 1). No other predictors were significant in predicting questionnaire return when the other variables were adjusted in a logistic regression model.

Based only on those who returned questionnaires, a logistic model using the same predictors was calculated to assess speed of return (table 2, column 2) and whether return was in response to a prompt (table 2 , column 3). None of the regression coefficients was sta-

Table 2 Logistic regression models predicting questionnaire return (no, yes), speed of questionnaire return (slow, fast), and return after a prompt (no, yes)

\begin{tabular}{|c|c|c|c|c|c|c|}
\hline \multirow[b]{2}{*}{ Model } & \multicolumn{2}{|c|}{$\begin{array}{l}\text { Ever return (no, yes) } \\
(n=311)\end{array}$} & \multicolumn{2}{|c|}{$\begin{array}{l}\text { Speed of return (slow, fast) } \\
(n=188)\end{array}$} & \multicolumn{2}{|c|}{$\begin{array}{l}\text { Return after prompt } \\
(\text { no, yes })(n=188)\end{array}$} \\
\hline & $\begin{array}{l}\text { Regression } \\
\text { coefficient }\end{array}$ & $\begin{array}{l}\text { Standard } \\
\text { error }\end{array}$ & $\begin{array}{l}\text { Regression } \\
\text { coefficient }\end{array}$ & $\begin{array}{l}\text { Standard } \\
\text { error }\end{array}$ & $\begin{array}{l}\text { Regression } \\
\text { coefficient }\end{array}$ & $\begin{array}{l}\text { Standard } \\
\text { error }\end{array}$ \\
\hline $\begin{array}{l}\text { Obstruction index } \\
\text { Restriction index } \\
\text { Bronchitis index } \\
\text { Age } \\
\text { Education } \\
\text { Smoking status } \\
\text { Marital status } \\
\text { Y-intercept }\end{array}$ & $\begin{array}{l}0.014 \\
0.000 \\
0.236 \\
0.047^{*} \\
0.064 \\
0.034 \\
0.160 \\
-3.531\end{array}$ & $\begin{array}{l}0.017 \\
0.012 \\
0.166 \\
0.011 \\
0.060 \\
0.259 \\
0.332 \\
2 \cdot 312\end{array}$ & $\begin{array}{r}-0.023 \\
0.015 \\
0.060 \\
-0.009 \\
-0.119 \\
-0.353 \\
0.099 \\
2.121\end{array}$ & $\begin{array}{l}0.020 \\
0.015 \\
0.191 \\
0.014 \\
0.080 \\
0.322 \\
0.456 \\
2.831\end{array}$ & $\begin{array}{r}-0.016 \\
0.003 \\
-0.284 \\
-0.020 \\
-0.089 \\
0.303 \\
0.465 \\
1.602\end{array}$ & $\begin{array}{l}0.021 \\
0.016 \\
0.210 \\
0.015 \\
0.086 \\
0.341 \\
0.501 \\
3.037\end{array}$ \\
\hline
\end{tabular}

${ }^{*} \mathrm{p}<0.001$. 
tistically significant in either model, indicating that those who respond late, or as a result of a prompt, were similar to other respondents in terms of the variables in the model.

\section{Discussion}

The results failed to show a statistically significant association between two objectively verifiable measures of health-obstruction and restriction-and postal questionnaire return. This finding is consistent with previous research showing that minor to moderate declines in spirometrically measured pulmonary function are seldom perceived by subjects. ${ }^{45}$

Self reported bronchitic symptoms, which by definition are perceived by subjects, have been related in other studies to labour force behaviour, such as sickness, absenteeism among workers in a Polish factory, ${ }^{46}$ and early retirement with disability among coalminers. ${ }^{47}$ In the present study bronchitic symptoms did not predict questionnaire return net of other variables in the model. Finally, neither speed of return nor return in response to a prompt was predicted by any of the variables in the model. In sum, the hypothesis that health status stimulates response by making a health related questionnaire more important to the respondent was not supported.

The data reported here suggest that response rate, speed of return, and response to a prompt are not related to bias in estimation of objective or perceived health parameters from sample data. To that degree the case for postal surveys for health assessment is strengthened. Nevertheless, some age bias in return rate was evident. When age is correlated with health status, any age bias in sampling would imply a health status bias. Fortunately, in many sample studies it is feasible to adjust for age bias by standardisation, particularly if age bias is suspected.

\section{References}

1 Babbie E. Social research methods. 3rd rev. Belmont, CA: Wadsworth Publishing Co, 1983.

2 Trager J, ed. The people's chronology. New York: Holt, Rinehart and Winston, 1979.

3 Whitney FP. The questionnaire craze. Education Review 1924;68:139-40.

4 Heberlein TA, Baumgartner R. Factors affecting response rates to mailed questionnaires: a quantitative analysis of the published literature. American Sociological Review 1978;43: 447-62.

5 Baur EJ. Response bias in a mail survey. Public Opinion Quarterly 1947;11:594-600.

6 Britton JH, Britton JO. Factors in the return of questionnaires related to older persons. J Appl Psychol 1951;35:57-69.

7 Kivlin JE. Contributions to the study of mail-back bias. Rural Sociology 1965;30:323-6.

8 Hochstim JR, Athanasopoulos DA. Personal follow-up in a mail survey: its contribution and its cost. Public Opinion Quarterly 1970;34:69-81.
9 Kaplan S, Cole P. Factors affecting response to postal question- $Z$ naires. Br J Prev Soc Med 1970;24:245-7.

10 Zimmer $\mathbf{H}$. Validity of extrapolating non-response bias from mail questionnaire follow-up. J Appl Psychol 1956;40:117-21.

11 Mayer CS, Pratt Jr RW. A note on nonresponse in a mail survey Public Opinion Quarterly 1966;30:637-46.

12 Gannon MJ, Nothern JC, Carroll SJ Jr. Characteristics of non-ठㄷ respondents among workers. J Appl Psychol 1971;55:586-8. $\overline{\bar{\omega}}$

13 Oakes TW, Friedman GD, Seltzer CC. Mail survey response by health status of smokers, nonsmokers, and ex-smokers. Am Epidemiol 1973;98:50-5.

14 Criqui MH, Barrett-Connor E, Austin M. Differences between respondents and non-respondents in a population-based car- $\vec{O}$ diovascular disease study. Am J Epidemiol 1978;108:367-72. -

15 Goudy WJ. Nonresponse effects: studies of the failure of potentiat $\vec{\omega}$ respondents to reply to survey instruments. Monticello, Il:O Council of Planning Librarians, 1977.

16 Richardson WP, Higgins AC, Ames RG. Rates of attendance and $\stackrel{\mathbb{D}}{\mathcal{D}}$ reasons for non-attendance at a clinic of handicapping condi-? tions. Am J Public Health 1964;54:1177-83.

17 Greenland S. Response and follow-up bias and cohort studies. Am J Epidemiol 1977;106:184-7.

18 Criqui MH. Response bias and risk ratios in epidemiologic stud $-{ }^{2}$ ies. Am J Epidemiol 1979;109:394-9.

19 Siemiatycki J, Campbell S, Richardson L, et al. Quality of response in different population groups in mail and telephonesurveys. Am J Epidemiol 1984;120:302-14.

20 Vernon SW, Roberts RE, Lee ES. Ethnic status and participation in longitudinal health surveys. $A m \quad J$ Epidemiol 1984;119:99-113.

21 Gordon T, Moore FE, Shurtleff D, et al. Some methodologic problems in the long-term study of cardiovascular disease: observations on the Framingham study. $J$ Chronic Dis. 1959;10:186-206.

22 Public Health Service. Smoking and health. Report of the Advisory Committee to the Surgeon General of the Public Health Service. Washington: US Department of Health, Education, and Welfare, 1964:96-7, 113-6. (PHS Publ No 1103.)

23 Heilbrun L, Nomura A, Stemmermann G. The effects of nonresponse in a prospective study of cancer. $\mathrm{Am} J$ Epidemio 1982;116:353-63.

24 Paul O, Tepper MH, Phelan WH, et al. A longitudinal study of coronary heart disease. Circulation 1963;28:20-31.

25 Clark VA, Aneshensel CS, Frerichs RR, Morgan TM. Analysis of non-response in prospective study of depression in Los Angeles County. Internat J Epidemiol 1983;12:193-8.

26 Greenlick MR, Bailey JW, Wild J, Grover J. Characteristics of men most likely to respond to an invitation to be screened. $A m B$ J Public Health 1979;69:1011-5.

27 Abramson JH, Kark SL, Epstein LM, Hopp C, Peritz E, Maklerô A. A community health study in Jerusalem. Design and response. Isr J Med Sci 1979;15:725-31.

28 Wiley JA, Camacho TC. Life-style and future health: evidence from the Alameda County Study. Prev Med 1980;9:1-21.

29 Cobb S, King S, Chen E. Differences between respondents and non-respondents in a morbidity survey involving clinica examination. J Chronic Dis 1957;6:95-108.

30 National Center for Health Statistics. Cycle 1 of the health exam ination survey: sample and response. Washington: US GPOO 1974. (Vital and health statistics. series 11, No 1.) (DHEW publication No (HRA) 75-1292.)

31 Forthofer RN. Investigation of nonresponse in NHANES II. Am $J$ Epidemiol 1983;117:507-15.

32 Doll $\mathrm{R}$, Hill AB. Mortality in relation to smoking: ten years observations of British doctors. Br Med J 1964;i:1399-410 1460-7.

33 Burgess AM Jr, Tierney JT. Bias due to nonresponse in a maib survey of Rhode Island physicians' smoking habits-1968 $N$ Engl J Med 1970;282:908.

34 Comstock GW, Helsing KJ. Characteristics of respondents and 
nonrespondents to a questionnaire for estimating community mood. Am J Epidemiol 1973;97:233-9.

35 Heath CW. Differences between smokers and nonsmokers. Arch Intern Med 1958;101:377-88.

36 Seltzer CC, Bosse R, Garvey AJ. Mail survey response by smoking status. Am J Epidemiol 1974;100:453-7.

37 Siemiatycki J, Campbell S. Nonresponse bias and early versus all responders in mail and telephone surveys. Am $J$ Epidemiol 1984;120:291-301.

38 Dillman DA. Mail and telephone surveys: the total design method. New York: John Wiley \& Sons, 1978.

39 Goyder JC. Further evidence on factors affecting response rates to mailed questionnaires. American Sociological Review 1982;47:550-3.

40 Parkes WR. Occupational lung disorders. 2nd ed. London: Butterworths, 1982.

41 Knudson RJ, Slatin RC, Lebowitz MD, Burrows B. The maximal expiratory flow-volume curve. Am Rev Respir Dis 1976;113.
587-600.

42 MRC Committee on the aetiology of chronic bronchitis. Standardized questionnaires on respiratory symptoms. $\mathrm{Br} \mathrm{Med} \mathrm{J}$ 1960;ii: 1665 .

43 Ames RG, Attfield MD, Hankinson JF, Hearl FJ, Reger RB. Acute respiratory effects of exposure to diesel emissions in coal miners. Am Rev Respir Dis 1982;125:39-42.

44 Cox DR. The analysis of binary data. London: Methuen and Co, 1970.

45 Gottfried SD, Altos MD, Kelson SG, Cherniack NS. Perception of changes in airflow resistance in obstructive pulmonary disorders. Am Rev Respir Dis 1981;124:566-70.

46 Jedrychowski W. Sickness absence caused by chest diseases in relation to smoking and chronic bronchitis symptoms. $\mathrm{Br} J$ Ind Med 1976;33:243-8.

47 Ames RG, Trent RB. Respiratory impairment and symptoms as predictors of early retirement with disability in US underground coal miners. Am J Public Health 1984;74:837-8. 